\title{
Farklı damla sulama sistemleri ve sulama yönetiminin pamuk lif verimi, verim öğeleri ve lif kalitesine etkisi
}

\author{
The effects of different drip irrigation systems and irrigation management on cotton \\ lint yield, yield components and lint quality
}

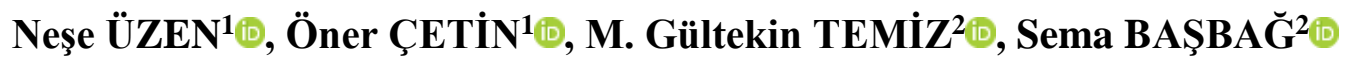

${ }^{1}$ Dicle Üniversitesi, Ziraat Fakültesi, Tarımsal Yapılar ve Sulama Bölümü, Diyarbakır

${ }^{2}$ Dicle Üniversitesi, Ziraat Fakültesi, Tarla Bitkileri Bölümü, Diyarbakır

Sorumlu yazar (Corresponding author): N. Üzen, e-posta (e-mail): nuzen@ dicle.edu.tr

Yazar(lar) e-posta (Authore-mail): oner_cetin@yahoo.com, mtemiz@dicle.edu.tr, sbasbag@dicle.edu.tr

MAKALE BILLGISİ

Alınıs tarihi 07 Eylül 2018

Düzeltilme tarihi 06 Kasım 2018

Kabul tarihi 19 Kasım 2018

\section{Anahtar Kelimeler:}

Yüzey damla

Yüzey altı damla

Pamuk

Lif verimi

Lif kalitesi

\section{$\ddot{0 ̈ z}$}

Bu çalıșma Diyarbakır koșullarında, 2016-2017 yıllarında, farklı damla sulama sistemleri ve farklı sulama suyu düzeyleri kullanılarak pamuk bitkisinde lif verimi, verim öğeleri ve lif kalite özelliklerinin belirlenmesi amacıyla yapılmıştır. Tesadüf bloklarında bölünmüș parseller deneme desenine göre 3 tekrarlamalı olarak kurulan denemede ana konuları farklı damla sulama yöntemleri ( $\mathrm{I}_{1}$ : Yüzey damla (YD), $\mathrm{I}_{2}$ : Yüzeyaltı damla $30 \mathrm{~cm}(\mathrm{YAD}), \mathrm{I}_{3}$ : Yüzeyaltı damla $40 \mathrm{~cm}$ ) alt konuları ise farklı sulama suyu düzeyleri $\left(\mathrm{K}_{1}: 1.25 \times \mathrm{ETc}\right.$ (bitki su tüketimi), $\mathrm{K}_{2}: 1.00 \times \mathrm{ETc}, \mathrm{K}_{3}: 0.75 \times \mathrm{ETc}$ ) oluşturmuştur. Sulama aralığ 5 gün olarak uygulanmıştır. Lif verimleri 2016 y1lında konulara bağlı olarak $1108-1734 \mathrm{~kg} \mathrm{ha}^{-1}$ arasında, 2017 yılında ise $1117-2457 \mathrm{~kg} \mathrm{ha}^{-1}$ arasında değissmiștir. En yüksek lif verimleri her iki deneme yılında da $\mathrm{I}_{3} \mathrm{~K}_{1}$ konusundan elde edilmiş olup, ortalama $2085 \mathrm{~kg} \mathrm{ha}^{-1}$ dır. Bütün damla sulama sistemlerinde sulama suyu arttıkça lif verimi de artmıstır. Benzer sekilde artan sulama suyu ve YD'dan YAD'a doğru gittikçe bitki boyunda artış sağlanmış olup en yüksek değer $(85.6 \mathrm{~cm}) \mathrm{I}_{3} \mathrm{~K}_{1}$ konusundan elde edilmiștir. En yüksek çırçır randımanı değeri ise $\mathrm{I}_{3} \mathrm{~K}_{1}$ konusundan $(\%$ 47.4) elde edilmiștir. Genelde su stresinin artması silkme oranını artırmıștır. Sulama suyu miktarı arttıkça lif kopma uzaması ve olgunluk indeksi de artmıştır. Farklı damla sulama sistemleri de lif kopma dayanıklılığını artırmıștır. Diğer lif kalite parametreleri arasındaki farklılıklar istatistiksel olarak önemli bulunmamışıtır. Lif verimi ve diğer özellikler bakımından en iyi sonuç $\mathrm{I}_{3} \mathrm{~K}_{1}$ konusundan elde edilmiş olmasına karşın, optimum su kullanımı göz önüne alındığında bitki su tüketiminin tam olarak verildiği ve $40 \mathrm{~cm}$ (YAD) derinliğe gömülü sulama sistemi olan $\mathrm{I}_{3} \mathrm{~K}_{2}$ konusu önerilmiştir.

\section{ARTICLE INFO}

Received 07 September 2018

Received in revised form 06 November 2018

Accepted 19 November 2018

\section{Keywords:}

Surface drip

Sub surface drip

Cotton

Lint yield

Lint quality

\section{ABSTRACT}

This study was carried out to determine the effects of drip irrigation systems and different amount of irrigation water on cotton lint yield, yield components and fiber quality in 2016-2017 years. The experiment was designed according to the split-plots with three replications. The main plots contained $\mathrm{I}_{1}$ : Surface drip irrigation, $\mathrm{I}_{2}$ : Subsurface drip irrigation $(30 \mathrm{~cm}), \mathrm{I}_{3}$ : Subsurface drip irrigation $(40 \mathrm{~cm})$. Sub-plots are $\mathrm{K}_{1}: \mathrm{I}=\mathrm{ETc} \times 1.25$, $\mathrm{K}_{2}: \mathrm{I}=\mathrm{ETc} \times 1.0$ ve $\mathrm{K}_{3}: \mathrm{I}=\mathrm{ETc} \times 0.75$, and irrigation interval was 5 days. Lint yields varied between $1108-1734 \mathrm{~kg} \mathrm{ha}^{-1}$ for 2016 and $1117-2457 \mathrm{~kg} \mathrm{ha}^{-1}$ for 2017 depending on the treatments. The maximum lint yield $\left(2085 \mathrm{~kg} \mathrm{ha}^{-1}\right)$ was obtained from the treatment of $\mathrm{I}_{3} \mathrm{~K}_{1}$ in both experimental years. Lint yield increased depending on increasing amount of irrigation water. The plant maximum height $(85.6 \mathrm{~cm})$ and the highest ginning yield $(47.4 \%)$. were obtained from the same treatment $\left(I_{3} K_{1}\right)$. In general, increasing water stress increased the shedding rate. Different amounts of irrigation water increased the fiber elongation and maturity index. Different drip irrigation systems have also affected fiber strength, and the maximum values were obtained from the subsurface drip irrigation. There were no any statistically effects of different drip irrigation systems on other fiber quality parameters. Considering the optimum water use and the treatment $\left(\mathrm{I}_{3} \mathrm{~K}_{2}\right)$ in which crop water requirement was supplied consummately, the subsurface drip irrigation with depth of $40 \mathrm{~cm}$ has been recommended. 


\section{Giriş}

Pamuk önemli bir endüstri bitkisi olup, Güneydoğu Anadolu Bölgesi'nde ülkemiz pamuk üretiminin \%50'sinden fazlası üretilmektedir. Bunun yanında pamuk bölgede sulama suyunu en fazla kullanan bitkilerin başında gelmektedir. Geleneksel yüzey sulamaya göre, önceden yapılan araştırmalarda damla sulama \%30-40 arasında sulama suyunda tasarruf sağlayabilmektedir (Cetin ve Bilgel 2002). Bu nedenle pamuk gibi sıra bitkilerinde kullanımı yaygınlaşan damla sulama sistemlerinde, uygulanan sulama suyunun, uygulama miktar ve kriterlerinin doğru tespiti, yüzey damla (YD) ve yüzeyaltı damla (YAD) sulama sistemleri için son derece önemlidir.

Damla sulama yöntemlerinde su ve besin elementi kullanım etkinliğinin yüksek olması, verim ve kalitede artış sağlaması, sulama suyunun kontrollü uygulanarak derine sizma kayıplarının en az olması, toplam sulama suyu ihtiyacının azaltılması gibi önemli avantajları bulunmaktadır (Ayars ve ark. 1999). Pamuk veriminin YD sulama ile artış gösterdiği farklı araştırıcılar tarafından da belirtilmiştir (Smith ve ark. 1991; Ayars ve ark. 1998; Cetin ve Bilgel 2002).

Verim artışının sağlanmasında en önemli unsurlardan biri sulama suyu gereksiniminin doğru belirlenmesidir. Ülkemizde YD ile sulanan pamukta Pan buharlaşması ve/veya toprak nem takibi esaslı sulama programlanmasına yönelik önemli araştırmalar yapılmıştır. YD ile ilgili ülkemizin değişik bölgelerinde yapılan araştırmalarda hem uygulanan sulama suyu hem de elde edilen verim bakımından oldukça farklı sonuçlar elde edilmiştir (Dağdelen ve ark. 2005, Ertek ve Kanber 2000, Cetin ve Bilgel 2002). Bu da göstermektedir ki, farklı iklim koşullarında bu tür araştırmaların diğer bölgelerde özellikle sulama suyu verim ilişkileri yönünden aynı şekilde uygulanabilirliği bulunmamaktadır.

Damla sulama yönteminin farklı uygulama şekillerinden biri de laterallerin toprak altına gömüldüğü yüzeyaltı damla sulama yöntemidir. YAD sulama ile ilgili olarak Menemen/İzmir'de pamukta yürütülen bir araştırmada, farklı sulama aralıkları (3 ve 6 gün) ve pan buharlaşmasının farklı oranları esas alınarak sulama konuları denenmiştir. Lateral derinliğinin $30 \mathrm{~cm}$ olarak alındığı çalışmanın sonuçlarına göre, sulama aralıkları arasında önemli bir fark bulunmamış olup, en yüksek verim pan buharlaşmasının 0.90 katı sulama suyunun uygulandığ $\breve{l}_{\text {konudan }}$ elde edilmiştir. Ayrıca $30 \mathrm{~cm}$ derinlik, arazi sürümünde sorunlar oluşturmuştur (Şen ve ark. 2013). Hutmacher ve ark (1995) pamukta YAD ile yaptıkları araştırmada, bitki su tüketimi 575-850 $\mathrm{mm}$ arasında değişmiş olup, pamuk lif verimi ise 1 750-1 $900 \mathrm{~kg} \mathrm{ha}^{-1}$ arasında değişmiştir. En yüksek verim 700-800 mm su tüketimi durumunda meydana gelmiştir. Bordovsky ve Lyle (1998) pamukta LEPA (Low Energy Precision Application) ve YAD sistemlerini karşılaştırmıştır. Her iki sulama sisteminde günlük $2.5 \mathrm{~mm}, 5.0 \mathrm{~mm}$ ve $7.5 \mathrm{~mm}$ sulama suyu uygulamışlardır. YAD sulamada lif verimi sirasiyla 1233,1319 ve $1350 \mathrm{~kg} \mathrm{ha}^{-1}$ iken, LEPA'da ise ayn sirasiyla 1054,1230 ve $1278 \mathrm{~kg} \mathrm{ha}^{-1}$ olmuştur. LEPA'da düşük verimin nedeni buharlaşma kayıplarının fazla olmasına bağlanmıştır.

YAD kullanılmasıyla pamuk veriminde ve sulama suyu kullanım etkinliğinde artıș olduğu bildirilmiștir (Smith ve ark. 1991; Ayars ve ark. 1998). Plaut ve ark. (1996) YAD için laterallerin pamukta $40-50 \mathrm{~cm}$ derinliğe yerleştirilmesini önermişlerdir. $\mathrm{Bu}$ durumda pamuk bitki köklerinin, kuru topraktan, topraktaki suya ulaşmak için ulaşabileceğini bildirmişlerdir. YAD sistem maliyeti yetiştirilen bitki, damlatıcı sayısı, lateral aralığı, kontrol ünitesinde yer alan ekipmanların çeşitliliği (pompa, filtrasyon sistemleri, gübreleme ekipmanları vd) ile su kaynağının niteliği ve konumuna bağlıdır (Breazeale ve ark. 2000).

$\mathrm{Bu}$ araştırma ile, pamukta YD ve YAD sulamada, bitkinin günlük FAO-Penman-Monteith yöntemine göre tahmin edilen su tüketimine dayalı sulama uygulamaları yanında YAD'da farklı toprak derinliklerine yerleştirilen damlatıcı laterallerin pamuk lif verimi, verim öğeleri ve lif kalite özelliklerine etkisi araştırılmıştır.

\section{Materyal ve Yöntem}

Deneme yeri toprakları tuzluluk ve drenaj sorunu olmayan, potasyum ve kireç yönünden zengin, hafif alkali, fosfor ve organik madde içeriği ise düşük karakterdedir. Kil içeriği oldukça yüksektir (\%65) (Çetin ve ark. 2013).

Denemenin yürütüldügü Diyarbakır ilinde, yazları sıcak ve kurak, kışları ise 1 lık ve yağışı ıir iklim hâkimdir. Yıllık ortalama yağış miktarı $491 \mathrm{~mm}$ olup, bunun genellikle büyük bir kısmı kış aylarında ve erken ilkbaharda meydana gelmektedir. Y1llik ortalama, minimum ve maksimum sicakl1klar sirasıyla $15.8,8.8$ ve $22.5^{\circ} \mathrm{C}$ dir. Ortalama nispi nem $\% 54$ olup, Aralık ve Ocak aylarında ise \%77 civarında seyretmektedir. Sulamaların yoğun yapıldığı Temmuz ve Ağustos aylarında nispi nem \%15'e kadar düşmektedir. Buhar basıncı açığının maksimum olduğu bu aylarda buharlaşma miktarları da Türkiye ortalamalarının çok üzerindedir.

Denemede YD ve YAD sulama sistemi kullanılmıştır. YD ve YAD sulamada lateral aralığı her iki pamuk bitki sırasını sulayacak şekilde $1.40 \mathrm{~m}$, damlatıcı aralığ $40 \mathrm{~cm}$, damlatıc1 debisi ise yapilan infiltrasyon testleri sonucunda, $2.21 \mathrm{~h}^{-1}$ olarak belirlenmiştir. Sulama suyu pH's1 8.0, elektriksel iletkenliği ise $0.62 \mathrm{dS} \mathrm{m}^{-1}$ olup, sulama suyu kalitesi açısından önemli sorun gözlemlenmemiştir.

Araştırmada Stoneville-468 (ST 468) pamuk çeşidi kullanılmıştır (Harem 2007). Deneme, tesadüf bloklarında bölünmüş parseller deneme desenine göre 3 tekrarlamalı olarak yürütülmüştür. Ana konularda farklı damla sulama sistemleri, alt konularda ise FAO-56 Penman-Monteith (PM) yöntemine göre tahmin edilen bitki su tüketim değerleri esas alınarak hesaplanan sulama konuları yer almıştır. Deneme konuları Çizelge 1'de verilmiştir.

Çizelge 1. Tesadüf bloklarında bölünmüş parseller deneme desenine göre uygulanan deneme konuları.

Table 1. Experimental subjects applied to randomized block parcel trial design.

\begin{tabular}{ll}
\hline $\begin{array}{l}\text { ANA KONULAR } \\
\text { (Damla sulama sistemleri) }\end{array}$ & $\begin{array}{l}\text { ALT KONULAR } \\
\text { (Sulama suyu) }\end{array}$ \\
\hline $\mathrm{I}_{1}:$ Yüzey damla & $\begin{array}{l}\mathrm{K}_{1}: \text { FAO-56-PM'e göre hesaplanan } \\
\text { su tüketiminin (ETc)'nin } 1.25 \text { kat1 } \\
\text { sulama suyu olarak uygulamak }\end{array}$ \\
$\begin{array}{l}\mathrm{I}_{2}: \text { Yüzeyaltı damla, }(30 \mathrm{~cm} \\
\text { derinlikte) }\end{array}$ & $\begin{array}{l}\mathrm{K}_{2}: \text { ETc'nin } 1.00 \text { katını sulama suyu } \\
\text { olarak uygulamak }\end{array}$ \\
$\begin{array}{l}\mathrm{I}_{3}: \text { Yüzeyaltı damla }(40 \mathrm{~cm} \\
\text { derinlikte) }\end{array}$ & $\begin{array}{l}\mathrm{K}_{3}: \text { ETc'nin } 0.75 \text { katını sulama suyu } \\
\text { olarak uygulamak }\end{array}$ \\
\hline
\end{tabular}

Deneme konularına göre parsel alanı: $4.2 \times 8.0 \mathrm{~m}=33.6 \mathrm{~m}^{2}$ (Toplam 6 sıra ve her 2 siraya 1 lateral). Bitki sıra aralığı $0.7 \mathrm{~m}$ olup, her bir lateral 2 bitki sırasındadır. Sulama suyunun hesabı 
için, öncelikle, bitkinin seçilen sulama aralığındaki (5 gün) gerçek zamanlı FAO-PM yöntemine göre tahmin edilen su tüketimi hesaplanmış ve seçilen sulama konusuna göre uygulama yapılmıştır. Bu amaçla, bitki su tüketiminin tahmin edilmesinde ve/veya hesaplanmasında yaygın olarak kullanılan Eşitlik 1 kullanılmıştır (Allen ve ark. 1998).

$$
\mathrm{ETc}=\mathrm{Kc} \times \mathrm{ETo}
$$

Eşitlikte; ETc: Tahmin edilen bitki su tüketimi (mm), Kc: Bitki katsayıs1, ETo: Referans bitki su tüketimi (çim) (mm)'dir.

PM yöntemine göre tahmin edilen bitki su tüketimi (ETc) hesaplandıktan sonra, sulama suyu hesabında ETc'ye bağli olarak, aşağıda verilen Eşitlik 2 kullanılmıştır (Cetin ve Bilgel 2002).

$$
\mathrm{I}=\mathrm{A} \times \mathrm{ETc} \times \mathrm{K} \times \mathrm{P}
$$

Eşitlikte; I: Uygulanacak sulama suyu miktarı (L), A: Sulanacak parsel alanı $\left(\mathrm{m}^{2}\right)$, ETc: Tahmin edilen bitki su tüketimi (Penman-Monteith Yöntemine göre, deneme yeri iklim verileri kullanılmasıyla) (mm), K: Deneme gereği esas alınan katsayılar ve yüzde oranlar, P: Örtü yüzdesi (\%).

İlk sulamaya, 0-90 $\mathrm{cm}$ toprak derinliğindeki elverişli nem düzeyi \%40'a düştüğünde başlanmıştır ve toprağın $0-60 \mathrm{~cm}$ derinliği sistemle tüm parsellerde eşit olarak tarla kapasitesine getirilmiştir. Bundan sonra da sulama aralığı esas alınarak (5 gün) konuların uygulanmasına başlanmıştır. İlk sulamaya başlandığında örtü yüzdesi \%35'in altında olduğundan, örtü yüzdesi değeri \%35 olarak alınmıştır. Örtü yüzdesi değerleri \%35'i geçtiğinde ise gerçek ölçülen değerler kullanılmıştır (Keller ve Bliesner 1990).

Deneme konularının kaliteye olan etkisini saptamak amaciyla birinci el hasat sirasinda her konudan yeterli miktarda lif örneği alınarak lif kopma dayanıklılığı, lif uzunluğu, lif inceliği, lif parlaklığı, lif esnekliği ve kısa lif oranı gibi lif kalite özellikleri tespit edilmiştir.

Azotlu gübre $130 \mathrm{~kg} \mathrm{ha}^{-1} \mathrm{~N}$, fosforlu gübre $80 \mathrm{~kg} \mathrm{ha}^{-1} \mathrm{P}_{2} \mathrm{O}_{5}$ olarak eşit dozlar halinde fertigasyonla uygulanmıştır (Özer ve Dağdeviren 1986; Özer 1992; Karademir ve ark. 2005). Buna göre ekimle birlikte toplam uygulanacak net azot ihtiyacının 1/5'i 20-20-0 gübresi doğrudan toprağa uygulanmıştır. Geriye kalan miktar ise deneme konularına göre, 19-5-5-Mikro elementler içeren ticari toz (Compo Basaplant Blue) gübre fertigasyon tekniği ile uygulanmıştır. Fertigasyon her 2 sulamada bir (10 günde bir) uygulanmıştır (Çetin ve ark. 2013). Fertigasyon yöntemi ilk sulama ile başlayıp, koza olum dönemine kadar devam etmiştir.

\section{Bulgular ve Tartışma}

\subsection{Pamuk lif verimi}

Deneme yıllarında uygulanan konulara göre elde edilen pamuk lif verim sonuçları Çizelge 2'de verilmiştir. Lif verimleri, kütlü pamuk verimlerinin her konuya ait çırçır randımanı ile oranlaması ile bulunmuştur. Lif verimleri, deneme konularına bağlı olarak 2016 yılında, 1108.4-1734.9 $\mathrm{kg} \mathrm{ha}^{-1}$, 2017 y1lında ise 1117.4-2457.2 $\mathrm{kg} \mathrm{ha}^{-1}$ arasında değişmiştir.

Elde edilen verilere göre, en düşük lif verimleri YD sulamada elde edilirken, YAD sulamada lateral derinliği arttıkça lif verimi artmıştır. Ayrıca, uygulanan sulama suyu arttıkça lif verimi artmıştır. Buna göre, $40 \mathrm{~cm}$ derinliğe yerleştirilen YAD sulama sisteminde, ETc'nin 1.0 katı olan konuda lif verimi ortalama $1945 \mathrm{~kg} \mathrm{ha}^{-1}$ elde edilmiş ve sulama suyu miktarı ve lif verimi açısından anılan konu önerilebilir bulunmuştur (Çizelge 2).

Yapılan varyans analiz sonuçlarına göre konular arasında interaksiyon bulunmaması nedeni ile deneme konularının lif verim sonuçları birbirinden bağımsız değerlendirilmiştir (Çizelge 3). Buna göre, sulama suyu miktarı arttıkça ve YD'dan YAD sulamaya doğru lif veriminin arttığı belirlenmiştir.

Çizelge 2. Deneme konuları ve yıllara göre ortalama lif verimi $\left(\mathrm{kg} \mathrm{ha}^{-1}\right)$ ve uygulanan sulama suyu $(\mathrm{mm})$ miktarları.

\begin{tabular}{|c|c|c|c|c|c|c|c|}
\hline \multirow[b]{2}{*}{ Ana Konular } & \multirow[b]{2}{*}{ Alt konular } & \multicolumn{2}{|c|}{ Deneme yillarına göre verim $\left(\mathrm{kg} \mathrm{ha}^{-1}\right)$} & \multirow{2}{*}{$\begin{array}{l}\text { Ortalama verim } \\
\left(\mathrm{kg} \mathrm{ha}^{-1}\right)\end{array}$} & \multicolumn{2}{|c|}{$\begin{array}{c}\text { Deneme yıllarına göre uygulanan } \\
\text { sulama suyu miktarı }(\mathrm{mm})\end{array}$} & \multirow{2}{*}{$\begin{array}{l}\text { Ortalama sulama } \\
\text { suyu miktarı }(\mathrm{mm})\end{array}$} \\
\hline & & 2016 & 2017 & & 2016 & 2017 & \\
\hline \multirow{3}{*}{$\mathrm{I}_{1}$} & $\mathrm{~K}_{1}$ & 1677.0 & 2145.7 & 1911.3 & 606.2 & 675.9 & 641.1 \\
\hline & $\mathrm{K}_{2}$ & 1678.8 & 1856.9 & 1767.8 & 458.1 & 517.6 & 487.9 \\
\hline & $\mathrm{K}_{3}$ & 1040.4 & 1117.4 & 1078.9 & 310.2 & 303.1 & 306.7 \\
\hline \multirow{3}{*}{$\mathrm{I}_{2}$} & $\mathrm{~K}_{1}$ & 1734.9 & 2358.1 & 2046.5 & 604.6 & 676 & 640.3 \\
\hline & $\mathrm{K}_{2}$ & 1546.5 & 1874.9 & 1710.7 & 540.2 & 522.6 & 531.4 \\
\hline & $\mathrm{K}_{3}$ & 1108.4 & 1340.0 & 1224.2 & 337.8 & 364.1 & 351.0 \\
\hline \multirow{3}{*}{$\mathrm{I}_{3}$} & $\mathrm{~K}_{1}$ & 1712.2 & 2457.2 & 2084.7 & 661.5 & 685.8 & 673.7 \\
\hline & $\mathrm{K}_{2}$ & 1723.2 & 2165.9 & 1944.6 & 543.9 & 558.7 & 551.3 \\
\hline & $\mathrm{K}_{3}$ & 1542.2 & 1587.7 & 1564.9 & 363.2 & 375.6 & 369.4 \\
\hline
\end{tabular}

Table 2. Average fiber yield $\left(\mathrm{kg} \mathrm{ha}^{-1}\right)$ and applied irrigation water $(\mathrm{mm})$ according to trial subjects and years.

Çizelge 3. Deneme konularının ayrı ayrı pamuk lif verimine etkisi $\left(\mathrm{kg} \mathrm{ha}^{-1}\right)$.

\begin{tabular}{|c|c|c|c|c|c|c|c|}
\hline $\begin{array}{c}\text { Farklı damla } \\
\text { sulama sistemleri }\end{array}$ & 2016 & 2017 & Ort. & Farklı sulama suyu düzeyleri & 2016 & 2017 & Ort. \\
\hline $\mathrm{I}_{1}(\mathrm{YD})$ & $1465 b^{*}$ & $1707 \mathrm{~b}^{*}$ & 1586 & $\mathrm{~K}_{1}(1.25 \mathrm{xETc})$ & $1708 \mathrm{a}^{*}$ & $2320 \mathrm{a}^{*}$ & 1900 \\
\hline $\mathrm{I}_{2}(\mathrm{YAD}-30 \mathrm{~cm})$ & $1463 \mathrm{~b}$ & $1858 \mathrm{ab}$ & 1660 & $\mathrm{~K}_{2}(1.00 \times \mathrm{xTc})$ & $1650 \mathrm{a}$ & $1966 \mathrm{~b}$ & 1808 \\
\hline $\mathrm{I}_{3}(\mathrm{YAD}-40 \mathrm{~cm})$ & $1659 \mathrm{a}$ & $2070 \mathrm{a}$ & 1865 & $\mathrm{~K}_{3}(0.75 \times \mathrm{xTc})$ & $1230 \mathrm{~b}$ & $1348 \mathrm{c}$ & 1289 \\
\hline
\end{tabular}

Table 3. Effect of experimental subjects on cotton fiber yield $\left(\mathrm{kg} \mathrm{ha}^{-1}\right)$. 
Ortalama verimler ve sulama suyu esas alınarak, sulama suyu-lif verim ilişkisi arasında yapılan regresyon analizlerinde, YD sulama konusu için, sulama suyu lif verimi arasında $\mathrm{y}=375.8+2.53 \mathrm{X}\left(\mathrm{R}^{2}=0.90^{* *}, \mathrm{X}\right.$ : sulama suyu miktar1), YAD sulamada $(30 \mathrm{~cm}) \mathrm{y}=225.2+2.82 \mathrm{X}\left(\mathrm{R}^{2}=0.99 * *, \mathrm{X}\right.$ : sulama suyu miktarı) ve diğer YAD sulamada $(40 \mathrm{~cm})$ ise $\mathrm{y}=941.4+1.73 \mathrm{X} \quad\left(\mathrm{R}^{2}=0.98^{* *}, \quad \mathrm{X}:\right.$ sulama suyu miktarı $)$ biçiminde istatistiksel olarak \%1 önem düzeyinde doğrusal ilişkiler tespit edilmiştir.

Kısıtlı sulamanın yapıldığı $\mathrm{K}_{3}$ konusunda hem yıllar hem de diğer konular bazında incelendiğinde lif verimi en düşük düzeyde elde edilmiştir. İsotçu ve Başal (2016)'ın yaptı̆̆ kısıtlı sulama çalışmasında \%50 düzeyinde verilen kısıntılı suyun, tam sulama koşullarına göre verimi $\% 26.6$ oranında azalttığını belirlemişlerdir. Yapılan diğer çalışmalarda kısıtlı sulamalarda verimin \%12 (Basal ve ark. 2009) ile \%28 (Karademir ve ark. 2011) arasında azaldığı bildirilmiştir.

\subsection{Pamuk verim öğeleri}

Farklı damla sulama sistem ve farklı sulama suyu miktarına bağlı olarak 2016 ve 2017 yılında elde edilen pamuk verim öğelerine ilişkin veriler Çizelge 4 ve 5'de verilmiştir.

Bitki boyu yıllara göre değişmiş olup, 2016 yılında, $52.9-68.5 \mathrm{~cm}, 2017$ yilında ise 58.1-85.6 cm arasinda değişmiştir. İstatistiki bakımından bitki boylarında da farklı sulama suyu uygulamaları \%5 önem düzeyinde etkili olmuştur. Sulama suyu miktarı arttıkça bitki boyu artmıştır. Denemedeki verim sonuçlarına paralel olarak, YAD sulama uygulamasında da bitki boyu değerleri daha yüksek olmuştur. Yapılan benzer çalışmalarda uygulanan su kısıtı oranı arttıkça bitki boyunda azalmalar meydana geldiği bildirilmiştir (Dagdelen ve ark. 2009).

Çizelge 4. Pamuk verim öğelerine ait veriler (2016).

Table 4. Cotton yield components data (2016).

\begin{tabular}{|c|c|c|c|c|c|c|c|}
\hline Ana & Alt & $\begin{array}{c}\text { Bitki boyu } \\
(\mathrm{cm})\end{array}$ & $\begin{array}{l}\text { Meyve dalı } \\
\left(\text { adet bitki }{ }^{-1}\right)\end{array}$ & $\begin{array}{c}\text { Odun dalı } \\
\left(\text { adet bitki }{ }^{-1}\right)\end{array}$ & $\begin{array}{c}\text { Silkme oranı } \\
(\%)\end{array}$ & $\begin{array}{l}\text { Toplam koza } \\
\left(\text { adet bitki-1) }^{-1}\right)\end{array}$ & Çırçır randımanı (\%) \\
\hline \multirow{3}{*}{$\mathrm{I}_{1}$} & $\mathrm{~K}_{1}$ & 59.0 & 8.4 & 1.2 & 34.4 & 13.2 & 42.3 \\
\hline & $\mathrm{K}_{2}$ & 59.0 & 8.4 & 1.1 & 39.6 & 13.5 & 41.5 \\
\hline & $\mathrm{K}_{3}$ & 52.9 & 8.0 & 1.2 & 45.9 & 12.8 & 42.6 \\
\hline \multirow{3}{*}{$\mathrm{I}_{2}$} & $\mathrm{~K}_{1}$ & 62.8 & 10.1 & 2.0 & 29.9 & 14.8 & 42.3 \\
\hline & $\mathrm{K}_{2}$ & 63.3 & 9.0 & 1.4 & 33.0 & 13.4 & 41.4 \\
\hline & $\mathrm{K}_{3}$ & 57.2 & 8.9 & 1.0 & 39.3 & 12.6 & 41.9 \\
\hline \multirow{3}{*}{$\mathrm{I}_{3}$} & $\mathrm{~K}_{1}$ & 68.5 & 10.5 & 1.7 & 34.9 & 16.4 & 40.5 \\
\hline & $\mathrm{K}_{2}$ & 65.3 & 9.0 & 1.5 & 39.3 & 14.6 & 42.0 \\
\hline & $\mathrm{K}_{3}$ & 62.4 & 8.6 & 1.6 & 32.5 & 12.8 & 42.0 \\
\hline
\end{tabular}

Çizelge 5. Pamuk verim öğelerine ait veriler (2017).

Table 5. Cotton yield components data (2017).

\begin{tabular}{|c|c|c|c|c|c|c|}
\hline Ana & Alt & Bitki boyu $(\mathrm{cm})$ & Meyve dalı & Odun dalı & Toplam koza (adet bitki ${ }^{-1}$ ) & Çırçır randımanı (\%) \\
\hline \multirow{3}{*}{$\mathrm{I}_{1}$} & $\mathrm{~K}_{1}$ & 77.6 & 9.2 & 1.2 & 12.3 & 46.4 \\
\hline & $\mathrm{K}_{2}$ & 73.6 & 9.3 & 1.4 & 14.6 & 45.3 \\
\hline & $\mathrm{K}_{3}$ & 58.1 & 7.7 & 1.6 & 9.0 & 44.4 \\
\hline \multirow{3}{*}{$\mathrm{I}_{2}$} & $\mathrm{~K}_{1}$ & 79.6 & 9.5 & 1.5 & 16.3 & 45.1 \\
\hline & $\mathrm{K}_{2}$ & 73.4 & 7.9 & 1.7 & 8.8 & 44.7 \\
\hline & $\mathrm{K}_{3}$ & 67.3 & 7.6 & 2.1 & 9.6 & 44.4 \\
\hline \multirow{3}{*}{$\mathrm{I}_{3}$} & $\mathrm{~K}_{1}$ & 85.6 & 8.9 & 1.8 & 13.7 & 47.4 \\
\hline & $\mathrm{K}_{2}$ & 81.4 & 9.3 & 2.1 & 14.7 & 46.2 \\
\hline & $\mathrm{K}_{3}$ & 72.7 & 9.5 & 2.3 & 11.9 & 43.5 \\
\hline
\end{tabular}

Meyve dalı ve odun dalı sayısı değerleri arasında istatistiksel olarak önemli bir fark meydana gelmemiştir. Ancak hem meyve dalı hem de odun dalı sayısı değerlerinin sulama suyu arttıkça nispi olarak arttığı söylenebilir (Çizelge 4 ve 5).

Silkme oranı 2016 yılında ölçülmüş olup, su stresi arttıkça silkme oranının da arttığı görülmüştür. Silkme oranları arasında da uygulanan sulama suyu miktarları bakımından \%5 önem düzeyinde farklılık meydana gelmiş olup, su stresi olan özellikle $\mathrm{K}_{3}(\mathrm{ETo} \times 0.75)$ uygulamalarında silkme oranlarının daha yüksek olduğu görülmüştür. $\mathrm{Bu}$ durum, daha az sulama suyu uygulamalarında verim değerlerinin de neden daha az (silkme oranı yüksek) olduğunu da açıklamaktadır (Cetin ve Bilgel 2002).

Deneme konularında çırçır randımanı değerleri \%40.5-47.4 arasında değişmiştir. Buna göre, 2016 yılında yapılan istatistiki analiz sonuçlarına göre, yalnız sulama suyu uygulamaları çırçır randımanını \%1 önem düzeyinde etkilemiştir. 2017 yılında ise, farklı damla sulama sistemleri $\% 5$, sulama suyu uygulamaları ise \%1 önem düzeyinde çırçır randımanı üzerinde etkili olmuştur. Özkara ve Şahin (1993) yaptıkları çalışmada çırçır randımanını \%43-44 arasında tespit etmiştir. Kısıntılı sulama koşullarında Sezgin ve ark. (2001) bu değerleri farklı sulama suyu miktarlarına göre \%43-45 arasında belirlemiştir.

Toplam koza sayısı bakımından YAD uygulamasında daha yüksek değerler elde edilmiştir. Konular arasında, sulama suyu miktarları, \%1 önem düzeyinde farklılık meydana getirmiş olup, uygulanan sulama suyu arttıkça toplam koza sayısı da artmıştır (Cetin ve Bilgel 2002). Yapılan benzer çalışmalarda sulama suyu azalışına bağlı olarak koza sayısının da azaldığı gözlenmiştir (Dağdelen ve ark. 2009). 


\subsection{Pamuk lif kalite analiz sonuçları}

Hasat sonunda toplanan kütlü pamuklardan her parselden 500 gram ağırlığında örnekler çırçırlanıp hazırlanarak, pamuk lif kalite analizleri yapılmıştır. Denemelere ait lif kalite analizi sonuçları yıllarına göre Çizelge 6 ve 7'de verilmiştir.

Denemenin 2016 yılında lif uzunluğu 29.1-30.3 mm arasında değişmiştir. 2017 yılında ise $25.9-27.7 \mathrm{~mm}$ arasında değişmiştir. Her iki araştırma yılında da sulama suyu düzeyinin azalması lif uzunluğu değerlerinin de azalmasına neden olmuștur (Çizelge 6 ve Çizelge 7). Uygulanan sulama suyu miktarına bağlı olarak en az sulama suyunun verildiği $\mathrm{K}_{3}$ konularında en kısa lif uzunlukları görülmüştür. Denemenin 2016 y1lındaki tüm sulama konularından elde edilen lif uzunluğu değerleri 2017 yılı ile kıyaslandığında daha yüksek değerler elde edilmiştir. Özdil (2003)'e göre lifler 25.15-27.94 $\mathrm{mm}$ aras1 orta; 27.94-32.00 mm aras1 ise uzun kategoride yer almaktadır. Su stresinin lif uzunluğu üzerine etkileri incelendiğinde, değişik araştırmacılar tarafından hem zamana hem de lif uzama periyodu boyunca su stresinin süresine bağlı olarak değiştiği bildirilmiştir (McWilliams 2004; İsotçu ve Başal 2016). Ayrıca su stresinin lif uzunluğunu olumsuz yönde etkilediği çok sayıda bilimsel çalışma bulunmaktadır (Balkcom ve ark. 2006, Darawsheh 2010, Karademir ve ark. 2011).

Lif kopma dayanıklılı̆̆ açısından incelendiğinde 2016 y1lında 29.1-31.9 $\mathrm{g} \mathrm{tex}^{-1}, 2017 \mathrm{y}$ llinda ise 26.2-31.0 $\mathrm{g} \mathrm{tex}^{-1}$ arasında değişmiştir. Özdil (2003)'e göre 26-29 $\mathrm{g} \mathrm{tex}^{-1}$ arası sağlam, $>30 \mathrm{~g} \mathrm{tex}^{-1}$ ise çok sağlam grubuna girmektedir. Denemede lif kopma dayanıklılığı açısından incelendiğinde $\mathrm{K}_{3}$ konusunun (en az sulama suyu düzeyi) lif kopma dayanıklılığg değerlerini azalttığı görülmektedir. $\mathrm{Bu}$ deneme yılında mukavemet-lif kopma dayanıklılığını (str) $\left(\mathrm{g} \mathrm{tex}^{-1}\right)$ ise $\% 5$ önem düzeyinde farklı damla sulama sistemleri etkilemiștir. Lif mukavemet-kopma dayanıklılığı en fazla YAD sulamadan (40 $\mathrm{cm}$ ) elde edilmiş̧ir. Denemenin ikinci yılındaki değerler ilk yıldaki değerler ile kıyaslandığında daha düşük olduğu tespit edilmiştir. 2017 yılı verilerine göre, farklı damla sulama sistemleri lif kopma dayanıklılığını (str) $\left(\mathrm{g} \mathrm{tex}^{-1}\right) \% 5$ önem düzeyinde etkilemiş olup, en yüksek değerler 2016 yılında olduğu gibi YAD sulamadan $(40 \mathrm{~cm})$ elde edilmiştir. Lif kopma dayanıklılığına ilişkin incelenen çalışmalarda su stresinin lif kopma dayanıklılığı üzerine etkisinin düzenli olmadığı bildirilmiştir. Örneğin İsotçu ve Başal (2016) kısıtlı sulama uygulamasının lif kopma dayanıklılığını az da olsa (\%0.9) arttırdığını, Basal ve ark. (2009) ve Karademir ve ark. (2011) ise su stresinin lif kopma dayanıklılı̆gnı olumsuz yönde etkilediğini bildirmişlerdir.

Verilerin istatistik analiz sonuçları incelendiğinde, 2016 yılında, farklı sulama suyu miktarları lif kopma uzaması (Elg) ve olgunluk indeksini (Mat.) \%5 önem düzeyinde etkilemiştir. Buna göre sulama suyu miktarı arttıkça lif kopma-uzaması ve olgunluk indeksi de artmıştır. Lif kopma-uzaması (Elg) (\%) değerleri 2017 yılında yine önceki deneme yılına benzer şekilde (\%5 önem düzeyinde) sulama suyu miktarı arttıkça artmıştır. Ayrıca üst yarı ortalama lif uzunluğu $(\mathrm{mm})$ da \%5 önem düzeyinde sulama suyu arttıkça artmıştır. Bunun dışında diğer lif parametreleri üzerine deneme uygulamalarının önemli bir etkisi olmamıștır.

Çizelge 6. Pamuk lif kalite analiz sonuçları (2016).

Table 6. Cotton fiber quality analysis results (2016).

\begin{tabular}{|c|c|c|c|c|c|c|c|c|c|c|c|c|c|c|}
\hline Ana & Alt & Sci & Mic & Mat & Length & Amt & Unf & SFI & Str & Elg & $\mathrm{Rd}$ & $+b$ & Tr Area & $\operatorname{Tr} \mathrm{Cnt}$ \\
\hline \multirow{3}{*}{$\mathrm{I}_{1}$} & $\mathrm{~K}_{1}$ & 145 & 4.90 & 0.91 & 29.99 & 740 & 84.7 & 9.0 & 29.6 & 5.5 & 76.0 & 9.8 & 0.6 & 42.7 \\
\hline & $\mathrm{K}_{2}$ & 146 & 5.05 & 0.92 & 30.10 & 757 & 85.1 & 8.5 & 30.3 & 5.7 & 73.6 & 9.4 & 0.9 & 49.7 \\
\hline & $\mathrm{K}_{3}$ & 138 & 4.87 & 0.91 & 29.52 & 692 & 84.1 & 9.7 & 29.1 & 5.4 & 74.0 & 10.5 & 0.8 & 53.0 \\
\hline \multirow{3}{*}{$\mathrm{I}_{2}$} & $\mathrm{~K}_{1}$ & 149 & 5.25 & 0.93 & 29.78 & 742 & 86.1 & 8.0 & 30.3 & 5.8 & 74.8 & 9.9 & 0.7 & 44.7 \\
\hline & $\mathrm{K}_{2}$ & 149 & 5.10 & 0.93 & 30.33 & 709 & 85.1 & 8.1 & 30.9 & 5.7 & 57.5 & 10.1 & 0.5 & 37.0 \\
\hline & $\mathrm{K}_{3}$ & 142 & 4.84 & 0.90 & 29.07 & 699 & 84.7 & 9.5 & 29.3 & 5.2 & 73.4 & 10.3 & 0.7 & 53.7 \\
\hline \multirow{3}{*}{$\mathrm{I}_{3}$} & $\mathrm{~K}_{1}$ & 150 & 5.22 & 0.93 & 30.29 & 767 & 84.6 & 8.3 & 31.8 & 6.0 & 75.1 & 10.4 & 0.6 & 47.3 \\
\hline & $\mathrm{K}_{2}$ & 154 & 4.99 & 0.93 & 29.49 & 727 & 85.8 & 9.5 & 31.9 & 5.7 & 73.3 & 10.1 & 1.1 & 41.7 \\
\hline & $\mathrm{K}_{3}$ & 147 & 4.93 & 0.91 & 29.43 & 748 & 85.0 & 9.2 & 30.5 & 6.6 & 74.4 & 10.0 & 0.7 & 42.7 \\
\hline
\end{tabular}

Sci: İplik eğrilebilirlik indeksi, Mic: Lif inceliği (mic), Mat: Olgunluk indeksi (\%), Length: Üst yarı ortalama uzunluğu mm), Amt: Analiz edilen liflerin adedi, Unf: Uniformite İndeksi (\%), SFI: Kısa Lif içeriği (\%), Str: Mukavemet / Lif Kopma dayanıklılığ 1 (g tex $\left.{ }^{-1}\right)$, Elg: Elastikiyet / Uzama (\%), Rd: Parlaklık / Beyazlık derecesi, +b: Sarılık derecesi, Tr Area: Çepel Alanı (\%), Tr Cnt: Çepel sayısı.

Çizelge 7. Pamuk lif kalite analiz sonuçları (2017).

Table 7. Cotton fiber quality analysis results (2017).

\begin{tabular}{|c|c|c|c|c|c|c|c|c|c|c|}
\hline Ana & Alt & Sci & Mic & Mat & Length & Amt & Unf & SFI & Str & Elg \\
\hline \multirow{3}{*}{$\mathrm{I}_{1}$} & $\mathrm{~K}_{1}$ & 118 & 5.10 & 0.86 & 26.97 & 519 & 83.1 & 8.93 & 29.0 & 8.7 \\
\hline & $\mathrm{K}_{2}$ & 115 & 5.20 & 0.87 & 26.63 & 453 & 83.2 & 9.17 & 28.6 & 8.4 \\
\hline & $\mathrm{K}_{3}$ & 109 & 4.73 & 0.86 & 26.07 & 446 & 82.5 & 10.10 & 26.2 & 8.2 \\
\hline \multirow{3}{*}{$\mathrm{I}_{2}$} & $\mathrm{~K}_{1}$ & 128 & 4.97 & 0.86 & 27.75 & 524 & 84.8 & 7.73 & 29.2 & 8.8 \\
\hline & $\mathrm{K}_{2}$ & 116 & 5.05 & 0.86 & 26.84 & 491 & 82.6 & 8.90 & 29.4 & 8.6 \\
\hline & $\mathrm{K}_{3}$ & 107 & 5.18 & 0.87 & 25.93 & 502 & 82.8 & 9.87 & 26.2 & 8.1 \\
\hline \multirow{3}{*}{$\mathrm{I}_{3}$} & $\mathrm{~K}_{1}$ & 129 & 4.73 & 0.85 & 27.27 & 462 & 83.0 & 8.53 & 31.0 & 8.9 \\
\hline & $\mathrm{K}_{2}$ & 124 & 5.08 & 0.86 & 27.07 & 474 & 84.3 & 8.27 & 29.2 & 8.8 \\
\hline & $\mathrm{K}_{3}$ & 115 & 4.93 & 0.86 & 26.55 & 461 & 82.5 & 9.73 & 28.6 & 8.6 \\
\hline
\end{tabular}

Sci: İplik eğrilebilirlik indeksi, Mic: Lif inceliği (mic), Mat: Olgunluk indeksi (\%), Length: Üst yarı ortalama uzunluğu mm), Amt: Analiz edilen liflerin adedi, Unf: Uniformite İndeksi (\%), SFI: Kısa Lif içeriği (\%), Str: Mukavemet / Lif Kopma dayanıklılığ $\left(\mathrm{g} \mathrm{tex}^{-1}\right)$, Elg: Elastikiyet / Uzama (\%). 
Öte yandan, şiddetli su eksikliği eğer kozaların ilk olum döneminde meydana gelirse lif uzunluğu ve lif olgunluğu da hücre duvarlarındaki selüloz birikimi nedeniyle azaldığı bildirilmiştir (Radin ve ark. 1992). Reeves (2012), sulamanın lif kalitesine olan etkisinin çok daha karmaşık olduğunu, lif uzunluğu ve mikroner değerlerinin su ve sicaklık stresi gibi çevresel faktörlerden daha çok etkilendiğini, düşük su dozu uygulamalarının lif uzunluğu üzerine etkisinin olumsuz olduğunu, sulamanın erken dönemde sonlandırılmasının mikroner değerlerini iyileştirebileceğini bildirmiştir. Ayrıca, lif uzunluğu için en uygun sıcaklık dereceleri, 15 ile $21^{\circ} \mathrm{C}$ arasında olduğu (Gipson ve Joham 1968), koza gelişiminin ilk 3 haftasındaki orta derecedeki sicaklıklar $\left(20-25^{\circ} \mathrm{C}\right)$ lif uzunluğunda artışa neden olduğu (Hong ve ark. 1984), lif inceliği ve olgunlaşması ise $26^{\circ} \mathrm{C}^{\prime}$ ye kadar düzenli bir şekilde arttığ1, ancak $32^{\circ} \mathrm{C}^{\prime}$ de ise düştüğü bildirilmiştir (Reddy ve ark. 1999). Belirtilen bu açıklamalar ışığında, araştırmanın yapıldığ 1 bölgede, pamuk yetişme mevsimi ortalarında (Temmuz ve Ağustos) aylık sicaklık ortalamalarının $30-32^{\circ} \mathrm{C}$, maksimum ortalama sicaklık değerlerinin ise, $40^{\circ} \mathrm{C}$ 'yi geçtiği göz önüne alındığında, yukarıda belirtilen lif kalitesi üzerine sıcaklığın etkilerini doğrulamaktadır.

\section{Sonuç}

Farklı damla sulama sistemleri ve farklı sulama suyu düzeyleri pamuk lifi verimi, verim öğeleri ve lif kalite özellikleri üzerine önemli düzeyde etki yapmıştır. Deneme yılları ortalaması esas alındığında en yüksek lif verimi (2085 $\mathrm{kg} \mathrm{ha}^{-1}$ ) gerçek bitki su tüketiminin \%125 olarak uygulandığ 1 ve $30 \mathrm{~cm}$ derinliğe gömülü olan YAD konusundan $\left(\mathrm{I}_{2} \mathrm{~K}_{1}\right)$ elde edilmiştir. Ancak, $30 \mathrm{~cm}$ derinlikteki YAD uygulamasında sorunlar oluşturduğundan ve optimum koşullara göre $40 \mathrm{~cm}$ derinlikteki YAD ve bitki su tüketimi kadar sulama suyunun uygulandığ 1 konu $\left(\mathrm{I}_{3} \mathrm{~K}_{2}\right)$ önerilebilir bulunmuştur. Buna göre bu koşullarda $1945 \mathrm{~kg} \mathrm{ha}^{-1}$ lif verimi elde edilebileceği tespit edilmiştir. Sulama suyu miktarı arttıkça bitki boyu artmıştır. Silkme oranının, azalan sulama suyu ile birlikte arttığı (en düşük $\mathrm{I}_{1} \mathrm{~K}_{3}$ konusunda \%45.9) görülmüştür. Toplam koza sayısı da YAD uygulamasında daha yüksek olarak (2016 y1lı için $\mathrm{I}_{3} \mathrm{~K}_{1}$ konusundan 16.4 adet, 2017 y1l1 için $\mathrm{I}_{2} \mathrm{~K}_{1}$ konusundan 16.3 adet) tespit edilmiştir. Her iki araştırma yılında da sulama suyu düzeyinin azalması lif uzunluğu ve lif kopma dayanıklılığı değerlerinin de azalmasına neden olmuştur.

Sonuç olarak damla sulama ile sulanan pamukta $40 \mathrm{~cm}$ 'ye yerleştirilen YAD ve gerçek su tüketimi kadar sulama suyu uygulaması sulama suyu tasarrufu ve uygulamadaki kolaylık bakımından önerilebilir.

\section{Teșekkür}

$\mathrm{Bu}$ makalede yer alan veriler, TÜBİTAK 1150600 No'lu araştırma projesi Sonuç Raporu'nun bir bölümünden elde edilmiştir. Belirtilen projenin finansal desteğinin (bütçesi) tamamı TÜBİTAK tarafından sağlanmıştır. $\mathrm{Bu}$ nedenle kurumsal olarak TÜBİTAK'a teşekkür ederiz. Ayrıca, bu makalenin "Materyal ve Yöntem" bölümünün bir kısmı, ilgili proje verilerinden üretilen farklı makale veya yayın(lar)'ın yalnız "Materyal ve Yöntem" bölümlerinin bir kısmı ile benzerlik göstermektedir.

\section{Kaynaklar}

Allen RG, Pereira LS, Raes D, Smith M (1998) Crop evapotranspiration: Guidelines for computing crop water requirements. United Nations Food and Agriculture Organization, Irrigation and Drainage Paper 56, Rome.

Ayars JE, Schoneman RA, Soppe RW, Mead RM (1998) Irrigating cotton in the presence of shallow ground water, drainage in the $21 \mathrm{st}$ century: Food production and the environment. Proc. Seventh Int. Drainage Symposium, ASAE, Orlando, FL, March, pp. 82-89.

Ayars JE, Pheneb CJ, Hutmacherc RB, Davisa KR, Schonemana RA, Vaila SS, Meadd RM (1999) Subsurface drip irrigation of row crops: a review of 15 years of research at the Water Management Research Laboratory. Agricultural Water Management 42: 1-27.

Balkcom KS, Reeves DW, Shaw JN, Burmester HH, Curtis LM (2006) Cotton yield and fiber quality from irrigated tillage systems in the Tennessee Valley. American Society of Agronomy 98: 596-602.

Basal H, Dagdelen N, Unay A, Yilmaz E (2009) Effects of deficit drip irrigation ratios on cotton (Gossypium hirsutum L.) yield and fiber quality. Journal of Agronomy and Crop Science 195: 19-29.

Bordovsky JP, Lyle WM (1998) Cotton irrigation with LEPA and subsurface drip systems on the southern high plains. In Proc. Beltwide Cotton Conf. San Diego, CA, Jan. 5-9, pp. 409-412.

Breazeale D, Neufeld J, Myer G (2000) Feasibility of subsurface drip irrigation for alfalfa. Journal of the American Society of Farm Managers and Rural Appraisers 58-66.

Cetin Ö, Bilgel L (2002) Effects of different irrigation methods on shedding and yield of cotton. Agricultural Water Management 54: $1-15$.

Çetin Ö, Üzen N, Temiz MG, Sessiz A (2013) Güneş enerjisi kullanarak damla sulama ile sulanan pamukta fertigasyonda azotlu gübre yönetimi. Dicle Üni. Bilimsel Araştırmalar Koordinatörlüğü (Proje No: ZF-10-166) Desteklenen Araştırma Sonuç Raporu, Diyarbakır.

Dağdelen N, Yılmaz E, Sezgin F, Gürbüz T, Akçay S (2005) Effects of different trickle irrigation regimes on cotton (Gossypium hirsutum L.) yield in Western Turkey. Pakistan of Biological Sciences 8(10): 1387-1391.

Dağdelen N, Basal H, Yilmaz E, Gürbüz T, Akçay S (2009) Different drip irrigation regimes affect cotton yield, water use efficiency and fiber quality in western Turkey. Agricultural Water Management 96: 111-120.

Darawsheh MK (2010) Cotton fiber quality parameters response to cultivation system as influenced by limited and normal irrigation. Journal of Food, Agriculture \& Environment 8(2): 527-530.

Ertek A, Kanber R (2000) Determination of appropriate irrigation amount and interval using pan evaporation method on cotton. Turkish Journal of Agriculture and Forestry 24(2): 293-300 (with an English abstract in Turkish).

Gipson JR, Joham HE (1968) Influence of night temperature on growth and development of cotton (Gossypium hirsutum L.). 1. Fruiting and boll development. Agronomy Journal 60: 292-295.

Harem E (2007) Türkiye'de tescil edilen pamuk çeşitleri (1959-2007). Nazilli Pamuk Araştırma Enstitü Müdürlüğü yayınları. Yayın no: 65. Nazilli, Türkiye.

Hong JR, Jiang ZH, Wu JS, Chen YQ, Shi HX (1984). Influence of low temperature on cotton boll weight at the later stage. Shanghai Agricultural Science and Technology 4: 12-14.

Hutmacher RB, Phene CJ, Davis KR Vail SS, Kerby TA, Peters M, Hawk CA, Keeley M, Clark DA, Ballard D, Hudson N (1995) Evapotranspiration, fertility management for subsurface drip acala and pima cotton. Proceedings of 5th International Micro irrigation Congress, April 2-6, 1995, Orlando, Florida, USA, pp. 147-154. 
İsotçu Ç, Başal (2016) Tam ve kısıtlı sulama koşullarında pamuk (Gossypium hirsutum L.) döl sıralarının verim ve lif kalite özelliklerinin karşılaştırılması. Adnan Menderes Üniversitesi Ziraat Fakültesi Dergisi 13(2): 71-77.

Karademir Ç, Karademir E, Doran İ, Altıkat A (2005) Diyarbakır ekolojik koşullarında farklı azot ve fosfor uygulamalarının pamukta verim ve lif teknolojik özelliklere etkisi. Gaziosmanpaşa Üniversitesi Ziraat Fakültesi Dergisi 22(1): 55-61.

Karademir Ç, Karademir E, Gencer O (2011) Yield and fiber quality of F1 and F2 generations of cotton (Gossypium hirsutum L.) under drought stress conditions, Bulgarian Journal of Agricultural Science 17(6): 795-805.

Keller J, Bliesner RD (1990) Sprinkle and trickle irrigation. Published by Van Nostrand Reinhold, New York pp. 651.

McWilliams D (2004) Drought strategies for cotton. Cooperative Extension Service Circular College of Agriculture and Home Economics. http://www.cahe.nmsu.edu/pubs/circulars.

Özdil N (2003) Pamuk lif özelliklerinin ölçümü ve değerlendirilmesi. Pamukta Eğitim Semineri, 14-17 Ekim 2003, İzmir, s. 237-247.

Özer MS, Dağdeviren İ (1986) Harran Ovası koşullarında pamuğun azotlu gübre isteği. Köy Hizmetleri Araştırma Enstitüsü Müdürlüğü Yayınları No: 25, Şanlıurfa.

Özer MS (1992) Harran Ovası koşullarında pamuğun fosforlu gübre isteği, Köy Hizm. Araştırma Ens. Müd., Yayın No: 25, Rapor Serisi No: 17, Şanliurfa.

Özkara M, Şahin A (1993) Ege bölgesinde farklı sulama programlarının Nazilli-84 ve Nazilli-87 pamuk çeşidinin verim ve bazı kalite özelliklerine etkileri, Menemen Araştırma Enst. Md. Yayınları, Genel Yayin No: 193, Menemen.
Plaut Z, Carmi A, Grava A (1996) Cotton root and shoot responses to subsurface drip irrigation and partial wetting of the upper soil profile. Irrigation Science 16: 107-113.

Radin JW, Reaves LL, Mauney JR, French OF (1992) Yield enhancement by frequent irrigation during fruiting. Agronomy Journal 54: 551-557.

Reddy KR, Davidonis GH, Johnson AS, Vinyard BT (1999) Temperature regime and carbon dioxide enrichment alter cotton boll development and fiber properties. Agronomy Journal 91: 851858.

Reeves HR (2012) Effects of irrigation termination date on cotton yield and fiber quality. M.S. Thesis, Texas Tech Univ., Lubbock, TX.

Sezgin F, Yılmaz E, Dağdelen N, Baş S (2001) Pamuk tarımında farklı sulama yöntemi ve su düzeyi uygulamasının su-verim ilişkileri üzerine etkisi. 3. Ulusal Hidroloji Kongresi, 27-29 Haziran 2001, İzmir, s. 545-552.

Smith RB, Oster JD, Phene JC (1991) Subsurface drip irrigation produced highest net return in wasteland area study. California Agriculture 45(2): 8-10.

Şen S, Korkmaz N, Gündüz M, Kayam Y, Bilir L, Aşık Ş, Avcı M (2013) "Yüzeyaltı damla sulama ile sulanan pamuk ve misırın sulama programının oluşturulması”. Yıllık Sonuç Raporu. Uluslararası Tarımsal Araştırma ve Eğitim. Merkezi Menemen, İzmir. 